\title{
Autobiographically Significant Concepts: More Episodic than Semantic in Nature? An Electrophysiological Investigation of Overlapping Types of Memory
}

\author{
Louis Renoult ${ }^{1}$, Patrick S. R. Davidson ${ }^{2}$, Erika Schmitz ${ }^{2}$, Lillian Park ${ }^{3}$, \\ Kenneth Campbell ${ }^{2}$, Morris Moscovitch ${ }^{4}$, and Brian Levine ${ }^{4}$
}

\begin{abstract}
A common assertion is that semantic memory emerges from episodic memory, shedding the distinctive contexts associated with episodes over time and/or repeated instances. Some semantic concepts, however, may retain their episodic origins or acquire episodic information during life experiences. The current study examined this hypothesis by investigating the ERP correlates of autobiographically significant (AS) concepts, that is, semantic concepts that are associated with vivid episodic memories. We inferred the contribution of semantic and episodic memory to AS concepts using the amplitudes of the N400 and late positive component, respectively. We compared famous names that easily brought to mind episodic memories (high AS names) against equally famous names that did not bring such recollections to mind (low AS names) on a seman-
\end{abstract}

\section{INTRODUCTION}

Declarative memory is typically described as consisting of two independent, yet interacting, systems: episodic memory and semantic memory (Renoult, Davidson, Palombo, Moscovitch, \& Levine, 2012; Moscovitch et al., 2005; Tulving, 2002). Episodic memory itself is not unitary. At its core (some would argue its essence; Tulving, 2002) is the process of recollection, which enables the reexperiencing of events within their specific spatiotemporal contexts, along with the accompanying perceptual details (Rubin, Schrauf, \& Greenberg, 2003). Recollection can occur both at recall and recognition. Successful recognition of a stimulus, however, can also be accomplished via a general assessment of its familiarity (Yonelinas, 2002), without vividly reexperiencing the circumstances under which the stimulus was acquired. In contrast to these two forms of episodic memory, semantic memory contains our culturally shared general knowledge, such as knowledge of facts, events, objects, and people, also detached

\footnotetext{
${ }^{1}$ University of East Anglia, ${ }^{2}$ University of Ottawa, ${ }^{3}$ State University of New York College at Old Westbury, ${ }^{4}$ Rotman Research Institute, Baycrest, Toronto, Ontario, Canada
}

tic task (fame judgment) and an episodic task (recognition memory). Compared with low AS names, high AS names were associated with increased amplitude of the late positive component in both tasks. Moreover, in the recognition task, this effect of AS was highly correlated with recognition confidence. In contrast, the $\mathrm{N} 400$ component did not differentiate the high versus low AS names but, instead, was related to the amount of general knowledge participants had regarding each name. These results suggest that semantic concepts high in AS, such as famous names, have an episodic component and are associated with similar brain processes to those that are engaged by episodic memory. Studying AS concepts may provide unique insights into how episodic and semantic memory interact.

from the context of acquisition (Binder \& Desai, 2011; Tulving, 2002; Renoult, in press). Although distinguishable from one another, it is generally recognized that semantic and episodic memory interact, particularly at encoding and retrieval (e.g., Greenberg \& Verfaellie, 2010; Hanslmayr, Spitzer, \& Bauml, 2009; Greve, van Rossum, \& Donaldson, 2007; Klimesch, Schimke, \& Schwaiger, 1994). Here, we address a different question: To what extent does episodic memory and, in particular, recollection inform semantic concepts, and is such involvement reflected in the neural signatures accompanying the process? For example, I have the semantic knowledge that John Lennon was one of the Beatles, but I also have a recollection of what I was doing when I heard that he was killed. Does recollection contribute to my performance on semantic tests with respect to John Lennon, and if so, is there a neural signature that distinguishes this process from one in which no recollective process is engaged?

A common conception is that with time and/or repetition semantic memory emerges from episodic memory, shedding the distinctive contexts associated with the episodes (Moscovitch et al., 2005; Cermak, 1984; Cermak \& O'Connor, 1983). However, this process of "semanticization" does not necessarily imply that all semantic 
concepts become detached from related episodic memories. Some semantic concepts, such as names of people and locations, for instance, may retain their episodic origins or acquire episodic information during life experiences. Although current models of semantic memory assert that semantics is embodied in perception and action (Binder \& Desai, 2011; Barsalou, 2008; Martin, 2007), to our knowledge no model considers that some concepts might also be linked with and/or be embedded in episodes. Here, we examined this hypothesis by investigating autobiographically significant (AS) concepts, that is, semantic concepts that are associated with vivid ${ }^{1}$ episodic memories (reviewed in Renoult et al., 2012). For instance, in addition to general knowledge that Barack Obama is the current president of the United States, one may vividly recollect an argument with a friend as to whether he should be reelected or not. In initial work on this phenomenon, Westmacott and Moscovitch (2003) showed that, in healthy adults, famous names that brought to mind personal memories were associated with superior performance on tests of semantic and episodic memory compared with less personally significant famous names. This performance advantage for AS names was absent in Alzheimer disease and amnesic patients, two groups with severe episodic memory impairment due to medial-temporal lobe (MTL) damage (Westmacott, Black, Freedman, \& Moscovitch, 2004; Westmacott, Leach, Freedman, \& Moscovitch, 2001). In contrast, the performance advantage was preserved in semantic dementia patients who show marked deficits in their ability to remember semantic concepts, stemming primarily from anterior/lateral temporal lobe deterioration (see also Manning, Denkova, \& Unterberger, 2013). These results suggest that although famous names are thought to be represented in semantic memory, the performance advantage seen for AS names may derive from the additional influence of episodic memory.

One important aspect of this paradigm was that AS was incidental to task performance: It was established by ratings made by another group of participants (and corroborated by the participants themselves, but at the end of the experiment). The activation of relevant episodes by AS concepts may thus occur automatically. Such automatic activation of related episodes may result in MTL activation similar to that observed when processing certain concepts, such as those that are inherently autobiographical (e.g., names of friends) or those associated with self-referential strategies during semantic retrieval (e.g., birthday presents; Sheldon \& Moscovitch, 2012; Greenberg, Keane, Ryan, \& Verfaellie, 2009; Ryan, Cox, Hayes, \& Nadel, 2008).

AS concepts, which comprise both semantic and episodic memory, are not easily accommodated by current models of declarative memory that treat episodic and semantic memory as separate, even while acknowledging their possible interaction (Renoult et al., 2012; Moscovitch et al., 2005; Squire, 2004, Tulving, 2002). The goal of this study is to provide converging evidence from ERPs on the contribution of semantic versus episodic memory to AS concepts. Hypothesis-driven neuroimaging research can be useful in this respect by interrogating those brain systems robustly activated by episodic versus semantic probes. To our knowledge, the only related study of this nature used fMRI to compare names or faces of famous people high versus low in AS (Denkova, Botzung, \& Manning, 2006). High AS stimuli were associated with increased activity in a left lateralized network, including the parahippocampal gyrus, precuneus, ventrolateral pFC, TPJ, and fusiform gyrus. However, it is unclear from those results whether AS concepts differed from other concepts by the activation of episodic memories or simply by the activation of a more extended semantic network (i.e., one containing a greater number of semantic features), as suggested by the fact that the identified network of brain regions is similar to that seen in semantic memory studies (Binder, Desai, Graves, \& Conant, 2009). Moreover, participants were instructed to retrieve personal episodes related to the names during neuroimaging, potentially contaminating the evaluation of the neural correlates of AS concepts with the signal from explicit episodic retrieval.

In this study, we used ERPs to assess the neural correlates of semantic and episodic contributions to AS concepts. We focused on the N400 and the late positive component (LPC), which have been associated reliably with semantic processing (reviewed in Kutas \& Federmeier, 2011; Lau, Phillips, \& Poeppel, 2008; Van Petten \& Luka, 2006) and episodic recollection (reviewed in Voss \& Paller, 2008; Rugg \& Curran, 2007; Friedman \& Johnson, 2000), respectively. The $\mathrm{N} 400$ is a negative deflection, which develops between 200 and 500 msec after stimulus onset, with maximal amplitude at centroparietal electrode sites, and frequently exhibiting a right-sided maximum (Kutas \& Federmeier, 2011). The amplitude of N400 shows a systematic sensitivity to the processing of meaning. It has been shown to be modulated by any type of semantic relations, including category (e.g., Heinze, Muente, \& Kutas, 1998), functional (Bach, Gunter, Knoblich, Prinz, \& Friederici, 2009), synonymy (Liu, Perfetti, \& Hart, 2003), antonymy (Kutas \& Iragui, 1998), schema (Chwilla \& Kolk, 2005), world knowledge (Hagoort, Hald, Bastiaansen, \& Petersson, 2004), and arithmetic knowledge (Niedeggen, Rosler, \& Jost, 1999), but also associative relations (Franklin, Dien, Neely, Huber, \& Waterson, 2007) and the number of semantic features associated with meaningful stimuli (Rabovsky, Sommer, \& Abdel Rahman, 2012). Experiments that investigated the learning of new concepts in adults showed graded N400 activity, which was proportional to the amount of knowledge (Rahman \& Sommer, 2008) or number of features (Gratton, Evans, \& Federmeier, 2009) that had been acquired for these objects.

Neuropsychological studies report that left temporal or temporoparietal lesions produce significant reductions in N400 amplitude, a pattern that was associated with comprehension deficits but yielded no significant reductions in the amplitude of late parietal components (Friederici, 
Hahne, \& von Cramon, 1998; Swaab, Brown, \& Hagoort, 1997; Hagoort, Brown, \& Swaab, 1996).

The LPC, also designated as the "parietal old-new effect" or "parietal EM (episodic memory) effect," is a positive deflection that develops between 500 and $800 \mathrm{msec}$ after stimulus onset with maximum amplitude at posterior parietal sites and frequently exhibiting a left-sided maximum. It is considered to be a reliable index of episodic recollection (Voss \& Paller, 2008; Rugg \& Curran, 2007; Friedman \& Johnson, 2000). LPC amplitude varies with the amount of information recollected (e.g., Vilberg, Moosavi, \& Rugg, 2006; Wilding, 2000), the success of source monitoring judgments (Senkfor \& Van Petten, 1998; Wilding \& Rugg, 1996), and the degree of autonoetic awareness associated with retrieval (Curran, 2004; Duzel, Yonelinas, Mangun, Heinze, \& Tulving, 1997; Smith, 1993). Amnesic patients with bilateral lesions of the hippocampus show preserved N400 effects but an absence of LPC effects (Addante, Ranganath, Olichney, \& Yonelinas, 2012; Duzel, Vargha-Khadem, Heinze, \& Mishkin, 2001; Olichney et al., 2000), consistent with the role of this ERP component in episodic memory. As found for the N400 (Kutas \& Federmeier, 2011), the scalp distribution of the LPC varies with stimulus type, being more anterior for object and faces as compared with words (Galli \& Otten, 2011; Yick \& Wilding, 2008).

Finally, we also considered another ERP component: the frontal N400 (FN400) or midfrontal old-new effect. As its label implies, it has a more frontal scalp distribution compared with the more centroparietal scalp distribution of the classic N400. FN400 is often considered to be an index of familiarity (reviewed in Rugg \& Curran, 2007; Curran, Tepe, \& Piatt, 2006). For instance, the FN400 responds similarly to studied items and perceptually similar lures (Curran \& Cleary, 2003; Curran, 2000). However, the functional significance of the FN400 is still debated, with some investigators contending that FN400 and familiarity often co-occur but that this ERP component would be sensitive to conceptual priming (Voss, Lucas, \& Paller, 2012). Although we do not have a clear understanding of its function, we opted to include it for exploratory analyses and generating future hypotheses as to its functional significance.

We examined these ERP component correlates of high versus low AS famous names, first on a semantic task (fame judgment) and then on an episodic task (recognition memory). For both tasks, AS (i.e., personal memories associated with each name) was determined independently of task performance, using both normative data collected from a separate group of participants $(N=64)$ and ratings collected from each participant at the end of the experiment, replicating the original paradigm in which AS was incidental to task performance (Westmacott et al., 2004; Westmacott \& Moscovitch, 2003).

We hypothesized that if AS concepts differ from other concepts by being represented in episodic memory in addition to semantic memory, we should see clear dif- ferences in the amplitude of the LPC and/or the FN400 for high versus low AS concepts (Curran, 2004; Duzel et al., 1997; Smith, 1993). Conversely, if AS concepts differ from other concepts mainly by including more semantic features, high-AS concepts should be associated with greater N400 amplitudes than low-AS concepts (Rabovsky et al., 2012; Amsel, 2011; Laszlo \& Federmeier, 2011; Muller, Andoni Dunabeitia, \& Carreiras, 2010). Finally, if AS concepts reflect task-dependent interactions between episodic and semantic memory, we might find the N400 to be increased in the semantic task and the LPC and/or the FN400 in the episodic task. As reference measures of semantic and episodic memory in our participants, we compared, respectively, famous names high versus low in associated knowledge (i.e., number of facts $[\mathrm{NF}]$ ), as rated by our norming group, and high versus low confidence hits.

\section{METHODS}

\section{Normative Ratings}

\section{Stimuli}

One hundred twenty-five famous names were matched across occupational categories (an average of $25 \pm 1.5$ names in each of the following categories: actors, musicians, politicians, personalities, ${ }^{2}$ and athletes) and across the time of onset of fame (on average $20 \pm 2$ names for each of the following time periods: 1980-1984, 19851989, 1990-1994, 1995-1999, 2000-2004, and 20052010). Time of onset of fame for each famous name was operationalized as the first significant public event associated with the person, using Wikipedia (en.wikipedia. org/) and an additional source (e.g., official Web sites of celebrities, e.g., www.imdb.com for movie stars), when available. All names were famous at the time of the experiment (2011).

\section{Normative Rating of Stimuli}

We collected normative ratings of the degrees of fame and emotionality and numbers of facts (NF) and personal memories associated with each of the famous names. The norms were collected online using an Internet questionnaire (www.surveymonkey.com) completed by 64 participants between the ages of 20 and 35 years (mean age $=27 \pm$ 4 years; 20 men). They had completed on average $18 \pm$ 3 years of education, reported being free of neurological and psychiatric disorders, and had lived in Canada for most of their lives.

All variables (fame, emotionality, NF, personal memories) were evaluated using a 5-point scale, from $0=$ low to $4=$ high. Participants saw the name followed by a series of drop-down menus for each of the variables to be rated. Participants were free to respond in the order of their choice but had to rate all the names (max: 10 names per 
page) before going to the next page. After each page, fake questions were included such as "Please respond 4 to this question" or "Enter the current time" to verify that participants were responding correctly.

Fame was evaluated based on the frequency with which the name was encountered, as in previous studies (Westmacott et al., 2004; Westmacott \& Moscovitch, 2003): a 0 meant that the name appeared very rarely in public and a 4 meant that participants came across the name just about every day. Participants also had to report whether they had personal episodic memories associated with the names. A 0 rating meant that they had no personal memories for that name and a 1 that they had a personal association, but not a specific episode (e.g., having memories of watching movies starring an actor of that name, without remembering a specific episode when that occurred). The ratings of 2-4 meant that participants had a personal memory that was specific in time and place, with 2 being the less vivid and 4 being the most vivid. Participants also had to rate the emotionality associated with each name: 0 meant that the name did not evoke any emotion in the participant and 4 meant that it evoked a lot of emotion, whether positive or negative. Finally, participants had to report the NF that they knew about each name: 0 meant that they just knew that this person was famous and nothing else. 1 means that they knew 1 fact (e.g., he or she is an actor), whereas 4 meant that they knew at least 4 pieces of information.

On the basis of these normative data, we constructed two sets of names: 30 names high in AS and 30 names low in AS. The high AS names were associated with personal memories in the majority of participants (scores ranging from 2 to 4 in vividness of associated episodes in at least $70 \%$ of the norming participants) and the low AS names were associated with personal memories in only a minority of participants (scores ranging from 2 to 4 in at most $30 \%$ of the participants). Examples of names included Johnny Depp and Robin Williams (high AS) and Tiger Woods and Angelina Jolie (low AS).

These two sets of names were matched on degree of fame, time of onset of fame, NF, length (in letters), and frequency (using the Canada 411 phone directory) but differed in AS $(t=6.42, p<.001)$. In other words, the high versus low AS names were equally famous, and participants declared knowing as many pieces of information for each category, but these names differed in that only high AS names were associated with episodic memories. Also, AS did not interact with the age of the norming participants, $F(1,63)=0.38, p>.5$. As in previous studies (Denkova et al., 2006; Westmacott et al., 2004; Westmacott \& Moscovitch, 2003), these names were not matched for emotionality: Names high in AS were rated slightly higher in emotionality than names low in AS (1.8 vs. 1.35 on our $0-4$ scale, $t=3.02, p=.004)$. This was the case although we did not include any name that would have an obvious emotional association, such as names of murderers or crime victims.

\section{Experimental Tasks: Fame Judgment and Recognition Memory}

\section{Participants}

Nineteen right-handed participants took part in the fame judgment and the recognition tasks. They had normal or corrected-to-normal vision. None had taken part in the norming of the stimuli. They were recruited through poster advertisement on campus, among people between 20 and 35 years old (mean age $=25 \pm 4$ years; 9 men) who had completed on average $17 \pm 3$ years of education and had lived in Canada for most of their lives. Exclusion criteria included a history of head injury with loss of consciousness longer than $5 \mathrm{~min}$, and other neurological or medical conditions known to compromise brain function and also drug abuse. All participants signed an informed consent form accepted by the ethics board of the University of Ottawa. Participants were paid $\$ 15$ per hour of participation.

\section{Task 1: Fame Judgment}

Participants were seated comfortably in a dimly lit room in front of a computer screen placed $1 \mathrm{~m}$ from their eyes. E-Prime 2.0 (Psychology Tools, Inc., Pittsburgh, PA) was used for stimulus presentations. Each trial started with the presentation of a fixation cross at the center of the screen for 1 sec. Famous and nonfamous names, written in New Courier 12 font, were then presented for $2 \mathrm{sec}$ each in randomly intermixed order at the center of the screen in lower case. Participants were instructed to press one of two keyboard keys to indicate whether the presented name was famous or not. There were as many famous as nonfamous names (60 each). Each name was presented four times. Among the famous names, 30 were high in AS and 30 were low in AS (see Normative ratings section for more details). Between 1 and $1.5 \mathrm{sec}$ after the offset of the names, a blink instruction appeared for 1000 msec. The next trial began after an interval that randomly varied between 0.8 and $1.5 \mathrm{sec}$. The fame judgment served as the encoding task, but participants were not aware of the forthcoming recognition task.

\section{Task 2: Recognition Memory}

As in the fame judgment task, famous and nonfamous names were presented one at a time in randomly intermixed order at the center of the screen for $2 \mathrm{sec}$, preceded by the 1-sec fixation cross. Then, after an interval that varied between 0 and $500 \mathrm{msec}$, a prompt "Have you seen this name before in the experiment?" appeared for $3 \mathrm{sec}$ or until the participant responded (whichever came first). Participants were instructed to press one of two keyboard keys to indicate whether they had seen the name in the previous task (i.e., fame judgment) or not. Then, another prompt, "How sure are you?" appeared on the screen for 3 sec or until participants responded, with 
three possibilities the following: "Quite sure," "Relatively sure," "Not sure." Participants were instructed to use keyboard keys 1-3 to indicate their response, with 1 for "Quite sure," 2 for "Relatively sure," and 3 for "Not Sure" (see Stenberg, Hellman, Johansson, \& Rosen, 2009, for a similar design). In addition to the 60 famous names (30 names high in AS and 30 names low in AS) and 60 nonfamous names already presented in the first experiment, the stimulus set consisted of 60 new famous and 60 new nonfamous names drawn from the original pool (see above).

\section{Individual Rating of Personal Memories}

At the end of the experiment, participants completed a questionnaire in which they specified whether they had episodic/autobiographical memories associated with each of the famous names of the experiment. We thus obtained individual ratings for the famous names previously identified as high in AS and low in AS by the norming sample and used in the fame judgment and recognition task as well as for the 60 additional "new" famous names used in the recognition task. The same 5-point scale as in the online ratings was used. Names were subsequently binned for each participant into those rated 0-1 (low AS) versus 24 (high AS).

We also verified that there was general agreement between the norming sample and the participants of the experimental tasks (fame judgment and recognition tasks). Consistent with the normative ratings, $72.5 \%$ of the experimental participants had personal memories (scores ranging from 2 to 4 in vividness of the associated episodes) for the high AS names, whereas only $16.2 \%$ had personal memories for the low AS names.

\section{EEG Acquisition}

The EEG was recorded with a 63-channel active electrode system (Brain Products $\mathrm{GmbH}$ ) embedded in a nylon cap (10/10 system extended). An additional electrode was placed under the left eye to monitor vertical eye movements. The continuous EEG signal was acquired at a 500-Hz sampling rate using a right mastoid reference. The impedance was kept below $20 \mathrm{k} \Omega$. The high filter was set at $500 \mathrm{~Hz}$, and the time constant was $10 \mathrm{sec}$. A vertical EOG was reconstructed offline as the difference between the lower EOG and FP1 activity. A horizontal EOG was constructed by subtracting F7 from F8 activity.

Offline analyses were conducted using EEGLAB (Delorme \& Makeig, 2004) and ERPLAB (Lopez-Calderon \& Luck, 2014), two open source toolboxes running under Matlab 7.12 (R2011a, The Mathworks, Natick, MA). High- and low-pass filter half-amplitude cutoffs were set at 0.01 and $80 \mathrm{~Hz}$, respectively. An average reference was computed offline and used for all analyses. Before averaging, trials contaminated by excessive artifacts were rejected automatically with a step function (Luck, 2005) with a voltage threshold of $\pm 100 \mu \mathrm{V}$ in moving windows of $200 \mathrm{msec}$ and with a window step of $100 \mathrm{msec}$. This resulted in the following number of trials per condition: Fame Judgment task, high AS: $104.8 \pm 10$, low AS: $104.7 \pm 9$, high NF: $108.9 \pm$ 7, low NF: $107.2 \pm 7$. Recognition: high AS: $27.9 \pm 3$, low AS: $27.3 \pm 4$, correctly recognized old (hits): $98.9 \pm 13$, correctly recognized new: $97.2 \pm 11$, high NF: $54.2 \pm 7$, low NF: $55.4 \pm 9$.

The EEG was segmented into epochs of $1 \mathrm{sec}$ (from $-200 \mathrm{msec}$ before to $800 \mathrm{msec}$ after name onset). Only epochs containing correct responses were included in the ERP analyses. There were too few epochs in which errors were committed to permit reliable signal averaging. The amplitudes of the N400 and the LPC were measured as the mean of all data points between 300-500 msec and 500-700 msec, respectively. They were measured relative to the mean of all data points in the $200 \mathrm{msec}$ prestimulus baseline, using the baseline correction option of ERPLAP. Key electrode sites were grouped into three ROIs, each including eight electrodes (four for each hemisphere; see Figure 1). A centroparietal ROI, where the amplitude of the N400 is maximal (Curran, Tucker, Kutas, \& Posner, 1993), was chosen to measure this ERP component. It was comprised of electrodes $\mathrm{C} 1 / \mathrm{C} 2, \mathrm{C} 3 / \mathrm{C} 4, \mathrm{CP} 1 / \mathrm{CP} 2$, and $\mathrm{CP} 3 / \mathrm{CP} 4$. The LPC was measured using a posterior parietal ROI, where its amplitude is maximal (Rugg \& Curran, 2007; Friedman \& Johnson, 2000). It included electrodes P1/P2, P3/P4, P5/P6, and PO3/PO4. Finally, a frontal ROI was chosen to measure the FN400. It was centered around F3 and F4 electrodes, as is standard for FN400 ROIs (Rugg \& Curran, 2007; Curran et al., 2006). It comprised electrodes F1/F2, F3/F4, F5/F6, and AF3/AF4.

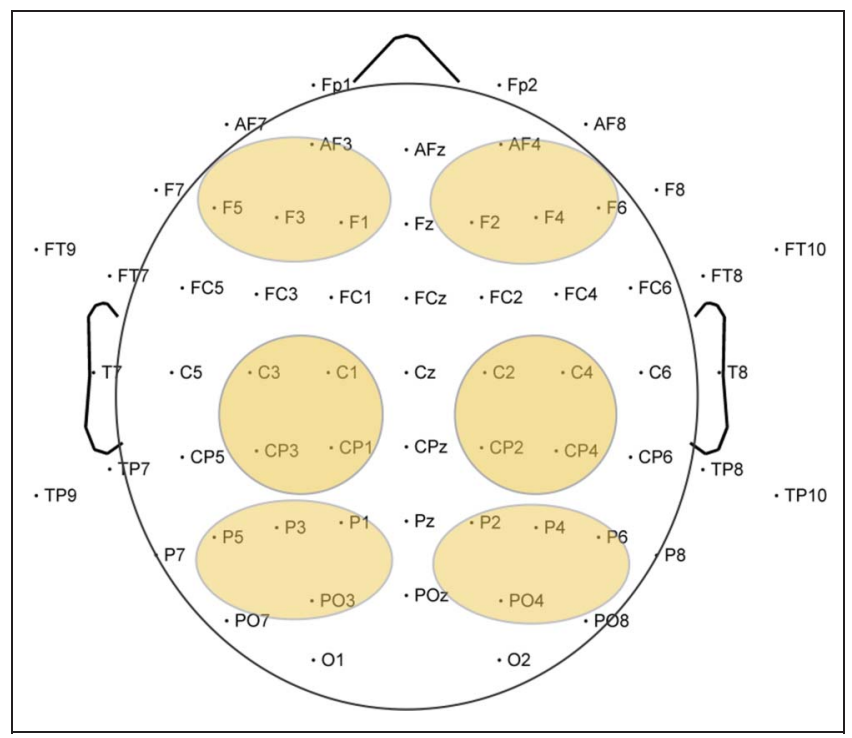

Figure 1. Scalp location of the three ROIs. A frontal ROI was used to measure the FN400. It included electrodes F1/F2, F3/F4, F5/F6, and $\mathrm{AF} 3 / \mathrm{AF} 4$. A centroparietal ROI was chosen to measure the N400. It comprised electrodes $\mathrm{C} 1 / \mathrm{C} 2$, C3/C4, CP1/CP2, and CP3/CP4. A posterior parietal ROI was used to measure the LPC. It included electrodes P1/P2, P3/P4, P5/P6, and PO3/PO4. 


\section{Statistical Analyses}

Fame judgment. We ran two repeated-measures ANOVAs on mean RTs. One had AS (high vs. low) and Repetition (four levels) as within-subject factors. The other had NF (high vs. low, based on the norming data) and Repetition (four levels) as within-subject factors. Another ANOVA was run on accuracy and had AS (high vs. low) as withinsubject factor.

For ERP data, repeated-measures ANOVAs were conducted with the same within-subject factors as the RT analysis plus a Hemisphere factor (right vs. left) and an Electrode factor (four electrodes). Separate ANOVAs were conducted for each ROI: frontal (FN400), centroparietal (N400), and posterior parietal (LPC). The Greenhouse and Geisser (1959) procedure was used to compensate for possible violations of the sphericity assumption associated with the electrode factor, when appropriate. In this case, the original degrees of freedom are reported together with the epsilon $(E)$ and the corrected probability level. For both behavioral and ERP data, partial eta-square $\left(\eta_{\mathrm{p}}^{2}\right)$ are indicated as measure of effect size.

Recognition memory. For analyzing behavioral data, we ran two repeated-measures ANOVAs of AS. One was performed on the success rate (percentage of correctly recognized old names) of normed stimuli and had AS (high vs. low) as within-subject factor. The other was performed on the individual ratings of AS and had this factor (high vs. low AS) as well as an Old-new factor (correctly recognized old vs. new) as within-subject factors. In addition, another ANOVA was performed on Confidence ratings (high, medium, low) as a within-subject factor.

For ERP data, repeated-measures ANOVAs were conducted with the same within-subject factors as the RT analysis plus a Hemisphere factor (right vs. left) and an Electrode factor (four electrodes). The same procedures were applied as in the fame judgment task, and only correct responses were included in the ERP analyses.

\section{RESULTS}

\section{Task 1: Fame Judgment}

\section{Behavioral Data}

The overall number of errors was low $(2.97 \pm 3.3)$, and there was no interaction between AS and the number of errors $(p>.5)$. Responses to normed high AS names were faster (mean RT $=793 \pm 112 \mathrm{msec}$ ) than were those to normed low AS names $(814 \pm 111 \mathrm{msec}), F(1,18)=$ $11.79, p=.003, \eta_{\mathrm{p}}^{2}=.39$. There was a main effect of Repetition, $F(3,54)=38.04, p<.001, \eta_{\mathrm{p}}^{2}=.64$, showing that RTs decreased as names were repeated (from $925 \pm$ 126 msec for Presentation 1 to $797 \pm 118 \mathrm{msec}$ at Presentation 4). The effect of Repetition did not interact with AS $(p>$.2). A similar effect was observed when we reran the
ANOVA based on the participants' own AS ratings (see Methods section): High AS names (mean RT $=783 \pm$ $111 \mathrm{msec}$ ) were associated with faster responses than were low AS names $(834 \pm 113 \mathrm{msec}), F(1,18)=36.07$, $p<.001, \eta_{\mathrm{p}}^{2}=.67$. This effect did not interact with the Repetition factor.

Analyses of mean RTs for the NF associated with each name revealed that names high in NF were associated with faster responses $(818 \pm 123 \mathrm{msec})$ than names low in NF (840 $\pm 132 \mathrm{msec}), F(1,18)=4.17, p=.04$, $\eta_{\mathrm{p}}^{2}=.24$. The effect of NF did not interact with Repetition $(p>.5)$.

\section{Electrophysiological Data}

FN400 time window. The repeated-measures ANOVAs on the mean voltage amplitudes in the FN400 time window showed no significant effect of the NF associated with each name (all $p s>.2$ ). The amplitude of the FN400 was similar for names high versus low in NF (see Figure 2A). There was no main effect of AS $(p>5)$ nor any interaction with the factors Repetition, Hemisphere, or Electrode (all ps > .2; see Figures 3A and 4). Similarly, no effect of AS was observed when averaging based on the participants' own ratings (all $p s>$.3).

N400 time window. The repeated-measures ANOVAs on the mean voltage amplitudes in the N400 time window revealed a significant effect of $\mathrm{NF}, F(1,18)=8.97, p=.007$, $\eta_{\mathrm{p}}^{2}=.29$. Names high in NF were associated with greater N400 amplitudes than were names low in NF (see Figure 2B). This effect had a centroparietal scalp distribution (Figure 2D) and appeared slightly greater over the right hemisphere (maximum amplitudes at $\mathrm{CP} 2$ and $\mathrm{CP} 4$ ). However, the interactions between NF and the Hemisphere and Electrode factors were not significant $(p>.2)$. Finally, there was no main effect of AS, nor any interaction with the factors Repetition, Hemisphere, or Electrode (all $p s>$.2). Thus, the amplitude of N400 did not differ between high and low AS names (see Figures 3B and 4). Very similar results were obtained when averaging based on the participants' own ratings (all $p s>.2$ ).

LPC time window. The repeated-measures ANOVAs on the mean voltage amplitudes of the LPC showed that the LPC was not modulated by NF (all $p s>.2$ ). In contrast, these analyses revealed a significant effect of AS, $F(1,18)=$ $8.09, p=.011, \eta_{\mathrm{p}}^{2}=.31$. The amplitudes of the LPC were greater for high AS than for low AS names (see Figures 3C and 4). This effect was found to be very similar when averaging was based on the participants' own ratings, $F(1,18)=7.02, p=.017, \eta_{\mathrm{p}}^{2}=.29$. There was a triple interaction between AS and the Electrode and Hemisphere factors, $F(3,54)=10.21, \mathrm{E}=0.86, p<.001, \eta_{\mathrm{p}}^{2}=.36$, illustrating that the effect of AS was greater over left than 


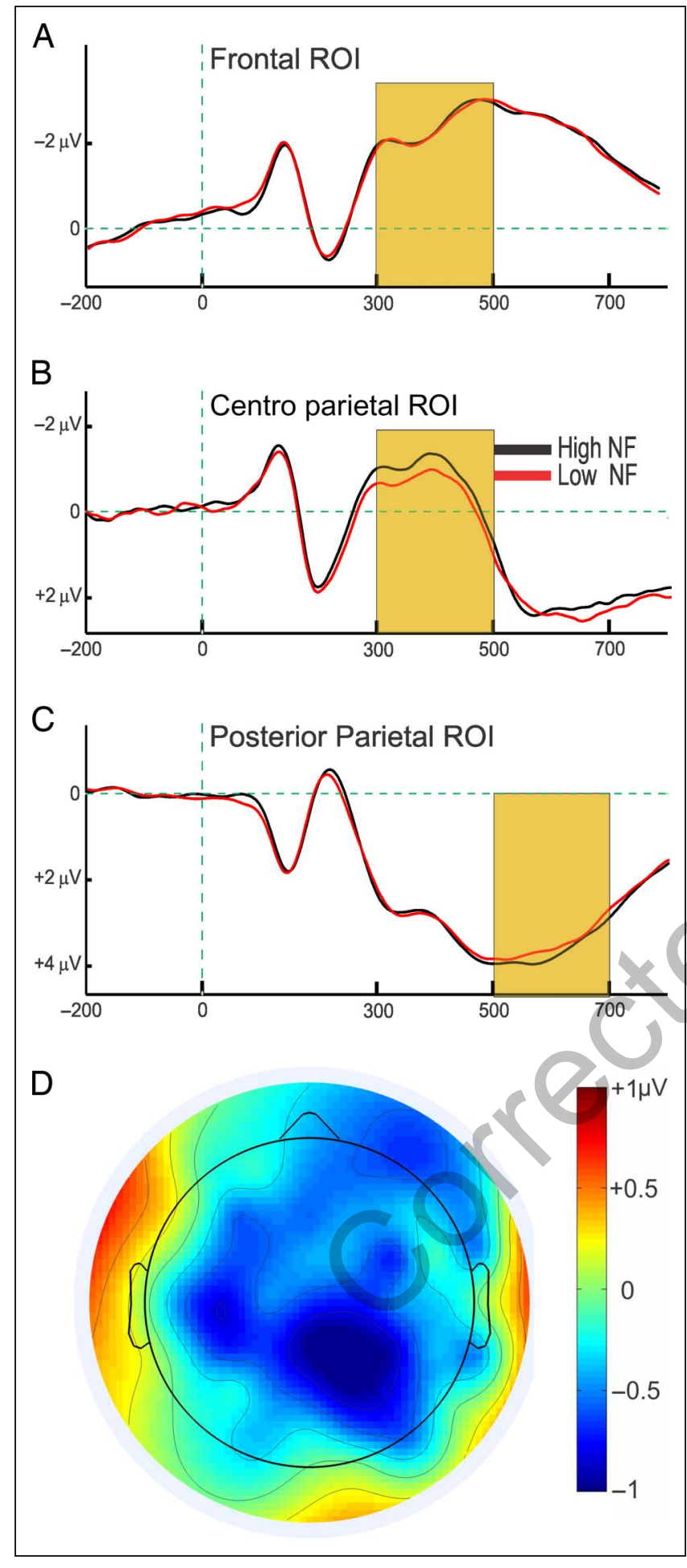

Figure 2. Grand-averaged ERPs $(n=19)$ to names high and low in $\mathrm{NF}$ in the fame judgment task. ERPs were averaged across the electrodes of the frontal ROI (A), centroparietal ROI (B), and the posterior parietal ROI (C). Negative voltage is plotted upwards. (D) Spline interpolated isovoltage maps of the effect of the NF in the 300-500 time window. These maps were obtained by subtracting the mean voltage of the grand mean ERPs evoked by names associated with a low NF from those associated with a high NF.
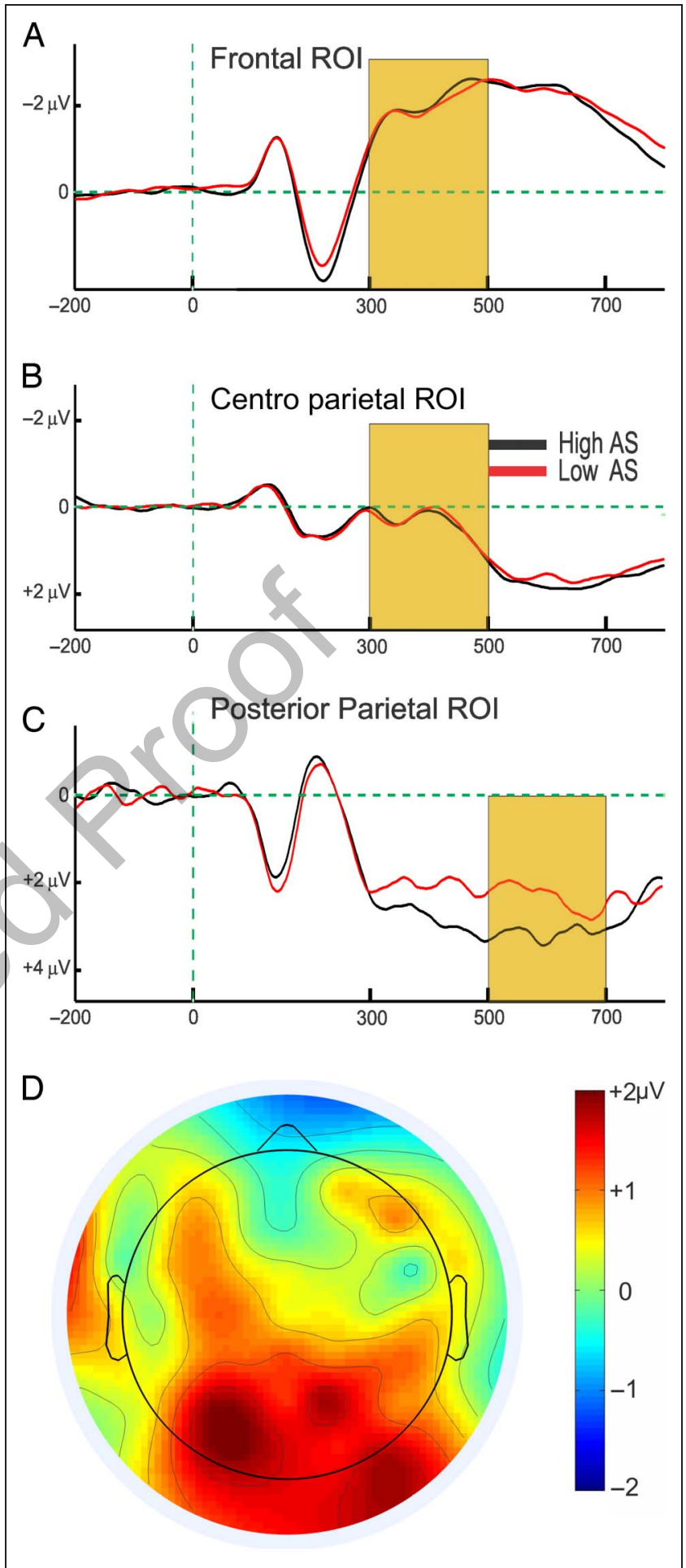

Figure 3. Grand-averaged ERPs $(n=19)$ to names high and low in AS in the fame judgment task. ERPs were averaged across the electrodes of the frontal ROI (A), centroparietal ROI (B), and the posterior parietal ROI (C; see Figure 1 for details on scalp locations). (D) Spline interpolated isovoltage maps of the effect of AS in the 500-700 time window. These maps were obtained by subtracting the mean voltage of the grand mean ERPs evoked by low AS names from those evoked by high AS names. 
right posterior sites (maximum amplitudes at $\mathrm{P} 3$ and $\mathrm{PO} 3$; see Figure 3D).

\section{Task 2: Recognition Memory}

As in the previous task, we report here the effects of AS based both on the norming study and on the participants' individual ratings. Note that the normed stimuli are the same as in the fame judgment task and are thus "old" stimuli in the recognition task. For these, we will thus report effects of AS on hit rate. For the individual ratings, for which scores were also available for the new stimuli, we will report main effects of AS and any interaction with the Old-new status of items.

\section{Behavioral Data}

The hit rate was $89 \%( \pm 15)$, and the correct rejection rate was $79 \%( \pm 14)$. For old stimuli, high AS names were associated with a slightly higher hit rate $(91 \pm 14 \%)$ than were low AS names ( $88 \pm 17 \%)$, but this difference only approached significance, $F(1,18)=4.2, p=.058, \eta_{\mathrm{p}}^{2}=$ .21. The effect of AS on hit rate was of greater magnitude $(87 \pm 20 \%$ for high AS vs. $76 \pm 25 \%$ for low AS;

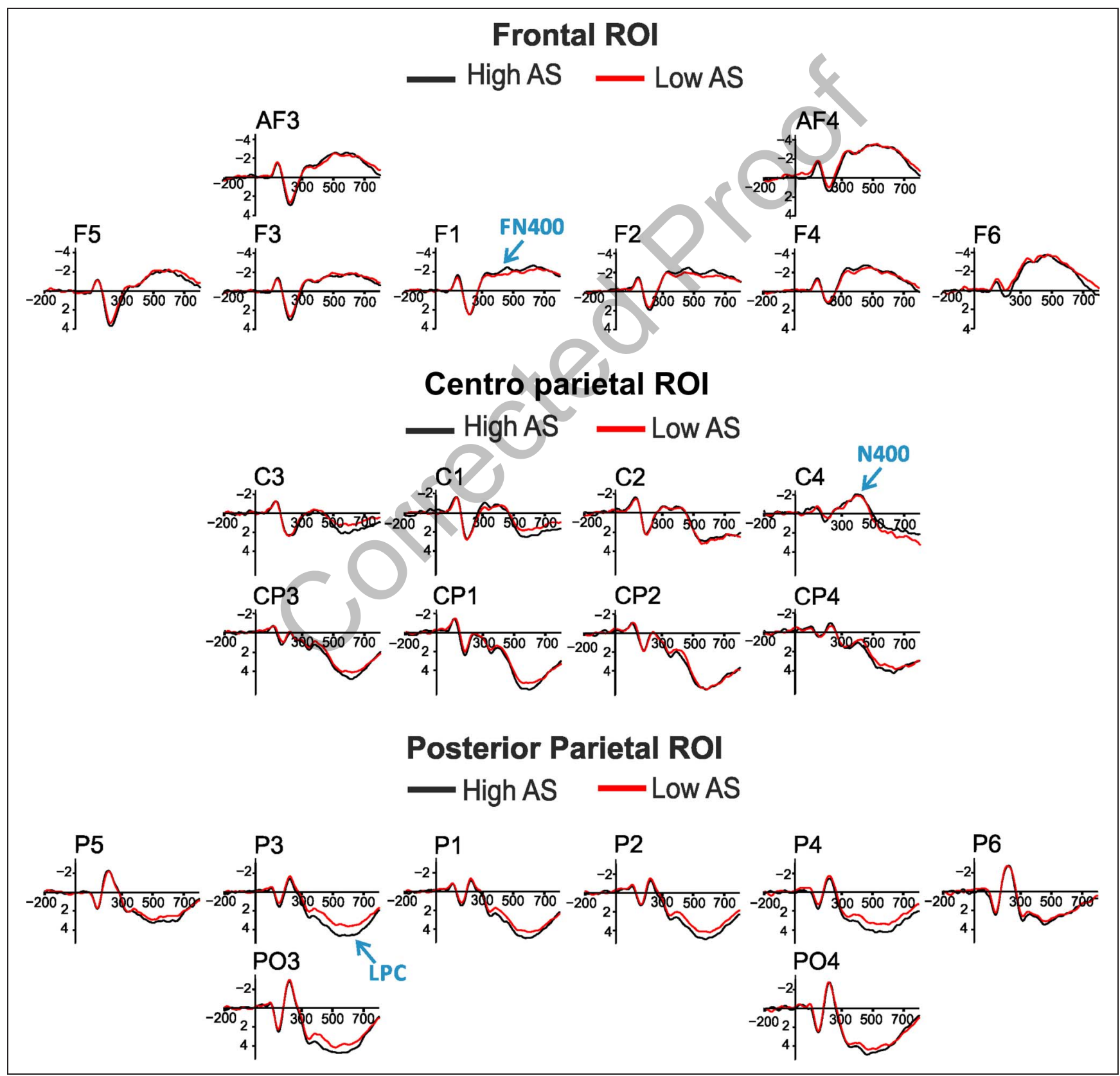

Figure 4. Grand-averaged ERPs $(n=19)$ to names high and low in AS in the fame judgment task showing individual electrodes composing the three ROIs: frontal, centroparietal, and posterior parietal. 
$\left.F(1,18)=5.29, p=.034, \eta_{\mathrm{p}}^{2}=.23\right)$, when averaging behavioral performances based on the participants' own ratings. There was no interaction with the Old-new status of items $(p>9)$, that is, the effect of AS was similar for hits and correct rejections (correct rejection rate: $86 \pm 15 \%$ for high AS vs. $75 \pm 15 \%$ for low AS). The corrected recognition score $(\mathrm{Pr})$ was 0.77 for high AS stimuli (bias measure $\mathrm{Br}$ : 0.6) and 0.63 (Br: 0.7) for low AS stimuli.

Confidence ratings did not differ $(p>.3)$ between high AS names (mean confidence $=1.05 \pm 0.1$ ) and low AS names (mean confidence $=1.08 \pm 0.1$ ). Very similar findings were observed when averaging based on the participants own ratings $(p>3)$. In contrast, confidence ratings differed when comparing all old (mean confidence $=1.1 \pm 0.1$ ) with all new stimuli (mean confidence $=1.5 \pm 0.2, F(1,18)=36.23, p<.001, \eta_{p}^{2}=$ .68). Participants thus made more confident recognition judgments for old than new stimuli.

\section{Electrophysiological Data}

FN400 time window. The repeated-measures ANOVAs on the mean voltage amplitudes in the FN400 time window showed no main effect of AS nor any interaction involving this factor (all $p s>1$ ), although the FN400 appeared slightly greater for high than low AS names (see Figures 5A and 6). There was a main effect of the Old-new status of items, $F(1,18)=5.78, p=.024, \eta_{\mathrm{p}}^{2}=$ .19. The amplitude of the FN400 was greater for correctly recognized old than new stimuli (see Figure $7 \mathrm{~A}$ and $\mathrm{D}$ ) and thus of opposite polarity as compared with posterior old-new effect (see below), replicating previous studies using the average reference (e.g., Curran \& Friedman, 2004; Curran \& Cleary, 2003; Curran, Tanaka, \& Weiskopf, 2002). This effect did not interact with electrode or hemisphere (all $p s>$.1). Finally, the FN400 appeared smaller for low than high and medium confidence ratings (see Figure 8A), but the effect of Confidence was not significant (all $p s>.1$ ). Similarly, there was no significant effect of NF (all $p s>.2$ ).

N400 time window. The repeated-measures ANOVAs on the mean voltage amplitudes in the N400 time window showed no effect of AS nor any interaction involving this factor (all $p s>$.5). N400 amplitudes thus did not differ between high and low AS names (see Figures 5B and 6). There was a main effect of the Old-new status of items, $F(3,54)=6.93, p=.014, \eta_{\mathrm{p}}^{2}=.22$. N400 amplitude was larger for correctly recognized new than old stimuli (Figure 7B). An interaction between the Old-new effect and Electrode factor approached significance, $F(3,54)=$ $2.35, \mathrm{E}=0.88, p=.08, \eta_{\mathrm{p}}^{2}=.09$, illustrating that the effect tended to be greater at electrodes CP4 and CP2 (see the scalp map of Figure 7D). The N400 was not modulated by confidence ratings (all $p s>.5$; see Figure $8 \mathrm{~B}$ ). Finally, there was no main effect of NF on the N400, but an interaction
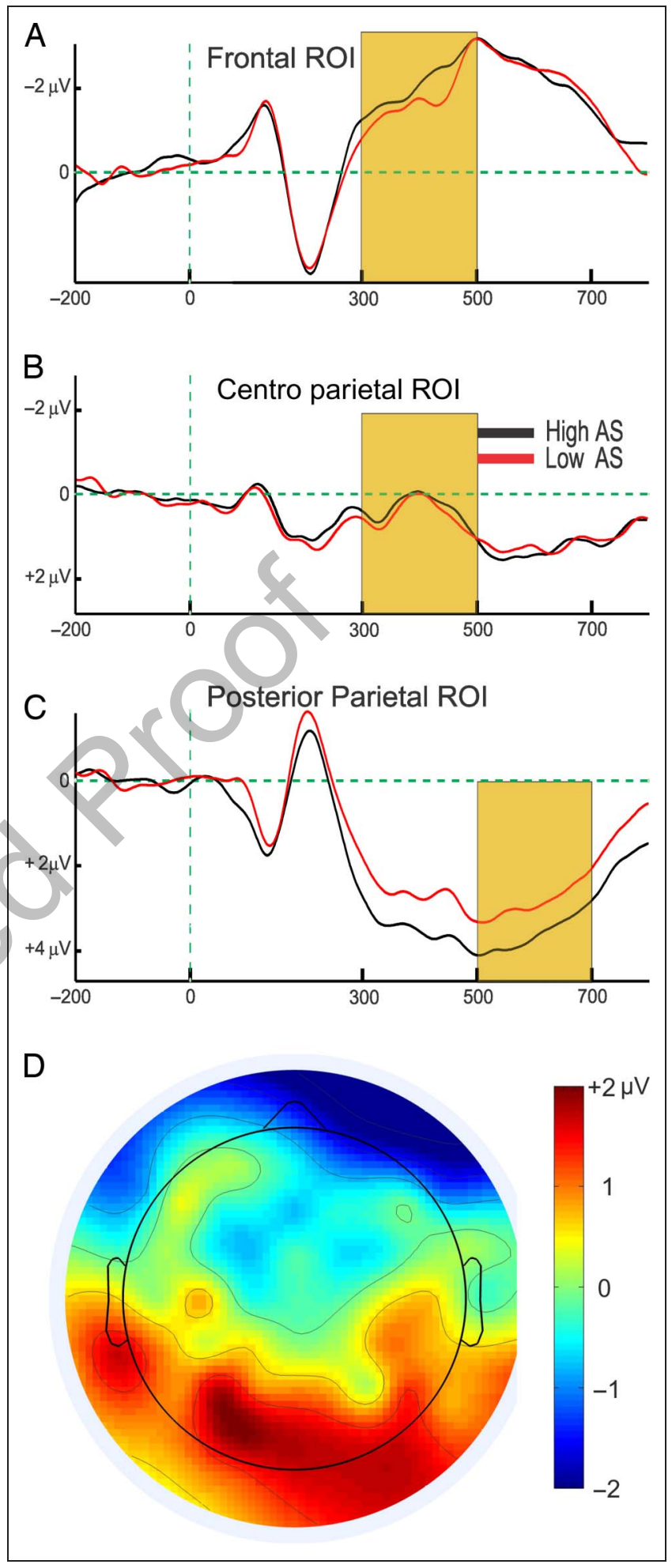

Figure 5. Grand-averaged ERPs $(n=19)$ to names high and low in AS in the recognition memory task. ERPs were averaged across the electrodes of the frontal ROI (A), centroparietal ROI (B), and the posterior parietal ROI (C; see Figure 1 for details on scalp locations). (D) Spline interpolated isovoltage maps of the effect of AS in the 500-700 time window. These maps were obtained by subtracting the mean voltage of the grand mean ERPs evoked by low AS names from those evoked by high AS names. 
between this variable and the Electrode factor approached significance, $F(3,54)=2.92, \mathrm{E}=0.76, p=.06, \eta_{\mathrm{p}}^{2}=.14$. Follow-up analyses showed that N400 amplitude was greater for names high in NF than low in NF at C1/C2 electrodes, $F(1,18)=5.57, p=.03, \eta_{\mathrm{p}}^{2}=.25$.

LPC time window. The repeated-measures ANOVAs on the mean voltage amplitudes in the LPC time window revealed a main effect of $\mathrm{AS}, F(1,18)=6.39, p=.021$, $\eta_{\mathrm{p}}^{2}=.26$ : The amplitude of the LPC was greater for high AS names than low AS names (see Figures 5C and 6). A similar effect of AS was observed when averaging was based on the participants' own ratings, $F(1,18)=5.74$, $p=.027, \eta_{\mathrm{p}}^{2}=.24$. This effect had a left parietal scalp distribution (maximum amplitudes at $\mathrm{PO} 3$ and $\mathrm{P} 3$; see Figure 5D). However, the interactions between AS and the Electrode and Hemisphere factors were not significant $(p>1)$. There was no interaction between AS and the Old-new status of items $(p>8)$. There was, however, a main effect of the Old-new status of items: the LPC was greater for correctly recognized old than new stimuli, $F(1,18)=11.94, p=.003, \eta_{\mathrm{p}}^{2}=.39$ (see Figure $7 \mathrm{C}$ ). This

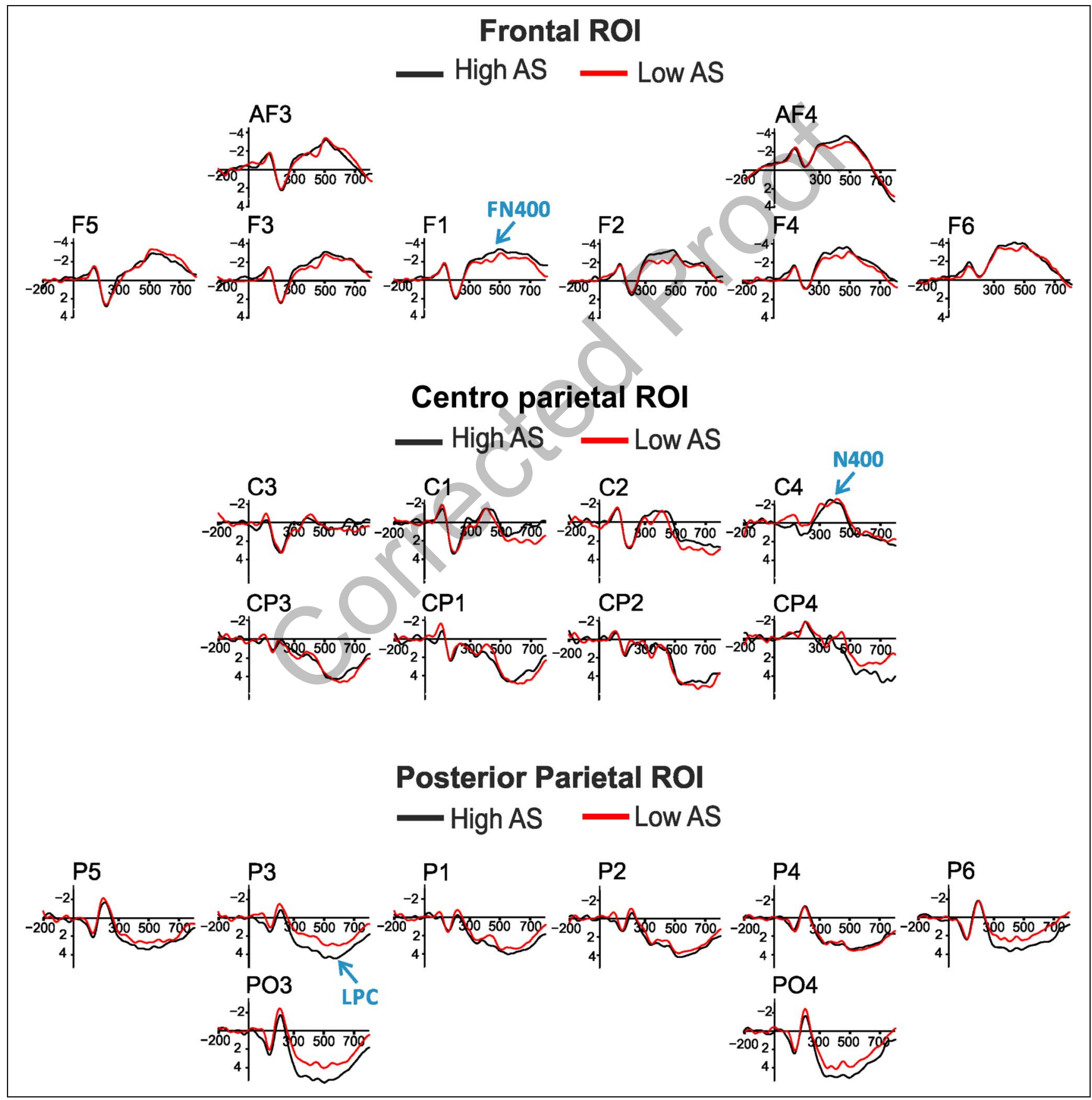

Figure 6. Grand-averaged $\operatorname{ERPS}(n=19)$ to names high and low in AS in the recognition memory task showing individual electrodes composing the three ROIs: frontal, centroparietal, and posterior parietal. 


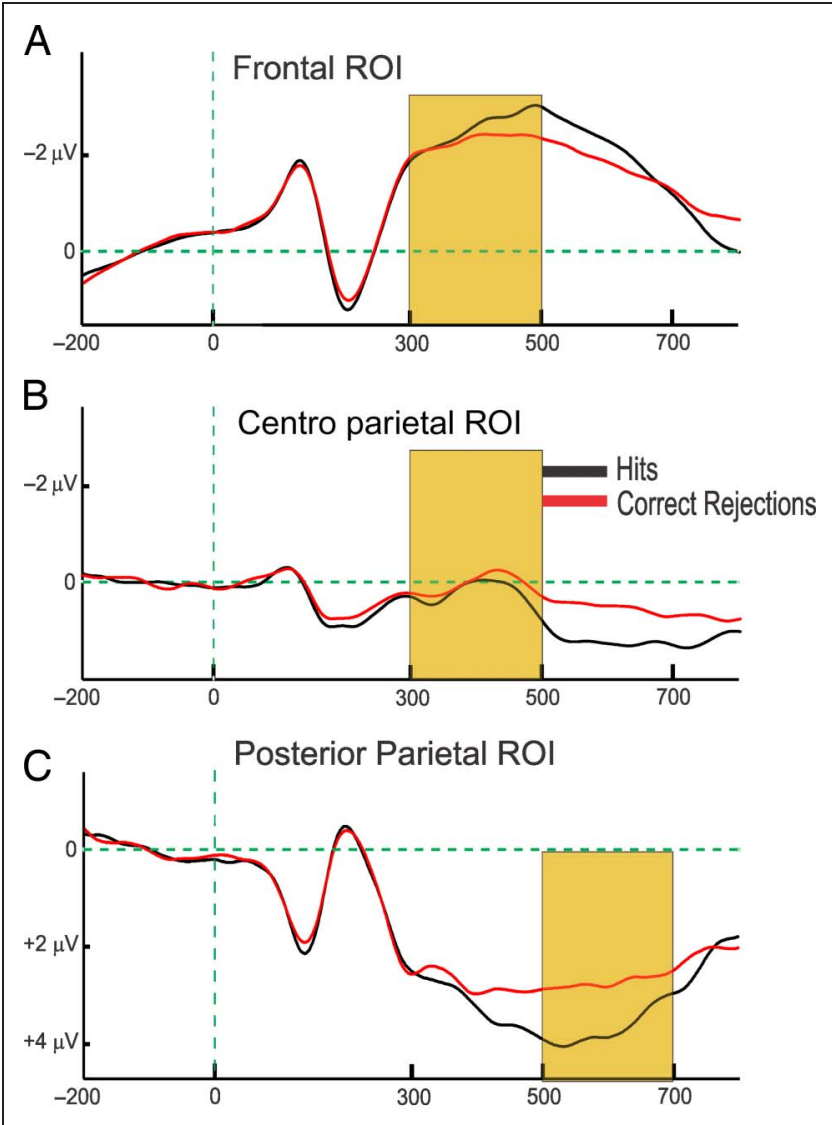

D

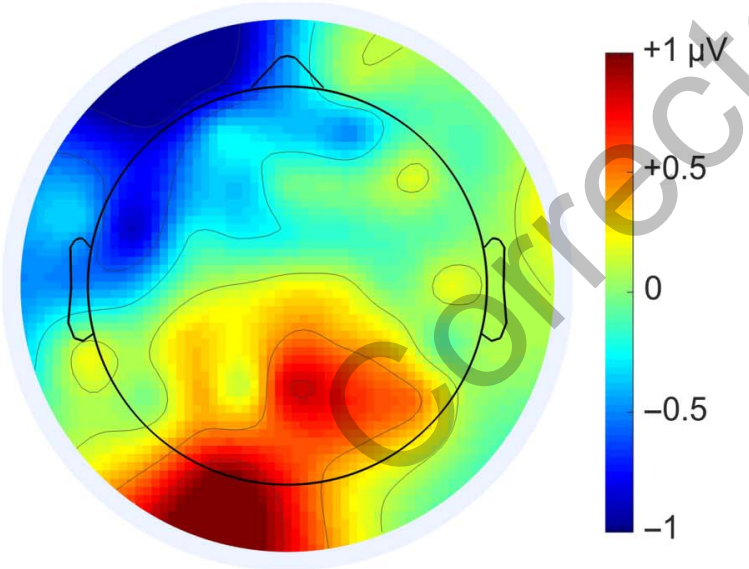

E

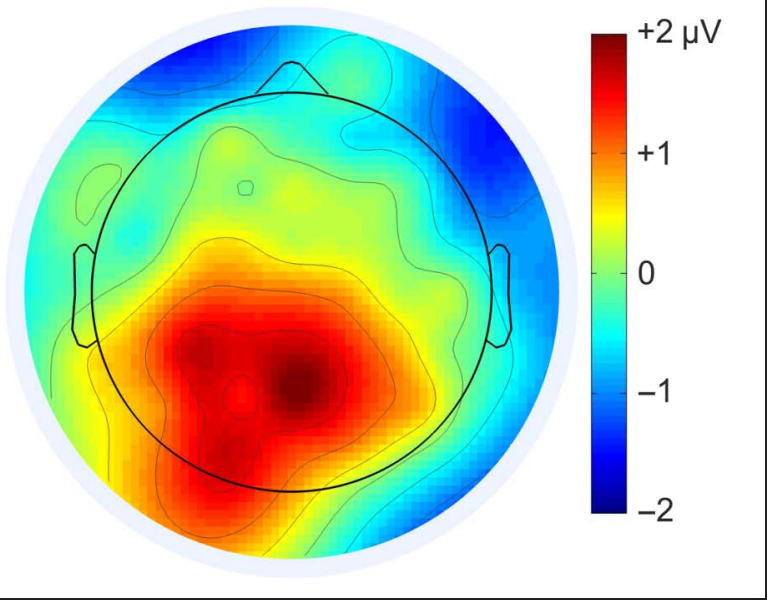

effect had again a left posterior parietal scalp distribution (maximum amplitudes at $\mathrm{CP} 3$ and $\mathrm{PO} 3$; see the scalp map of Figure $7 \mathrm{E}$ ), as illustrated by a triple interaction between Old-new and the Electrode and Hemisphere factors, $F(3$, $54)=4.61, \mathrm{E}=0.85, p=.009, \eta_{\mathrm{p}}^{2}=.204$. The LPC was also modulated by confidence ratings, $F(2,36)=5.1, p=$ $.04, \eta_{\mathrm{p}}^{2}=.201$ : its amplitude was greater for high (ratings of 1) versus low confidence items (ratings of 3 ), $F(1,18)=$ $4.76, p=.05, \eta_{\mathrm{p}}^{2}=.19$, but did not differ between medium confidence and high or low (see Figure 8C). This effect had a posterior parietal scalp distribution, with a slight leftsided asymmetry (maximum amplitude at PO3; see Figure 8D), but the interaction between Confidence and the Electrode and Hemisphere factors just missed significance, $F(3,54)=2.96, \mathrm{E}=0.74, p=.058, \eta_{\mathrm{p}}^{2}=.14$. Finally, as found in the fame judgment task, the NF did not modulate the amplitude of the LPC (all $p s>.2$ ).

Comparison of ERPs in the LPC time windows. Standard LPC effects are obtained for items high in recollection and retrieval success. Because we postulated that items high in AS would be accompanied by recollection, we should see an LPC effect for AS that was similar to that for retrieval success. Two additional repeated-measures ANOVAs were therefore conducted. First, a comparison of the factors AS (high AS minus low AS) and Recognition success (hits minus correct rejections) showed no main effect of Factor nor any interaction with Electrode and Hemisphere (all $p s>$.2). Second, a comparison of the factors AS and Recognition confidence (high minus low confidence hits) also revealed no main effect of Factor nor any significant interactions with other factors (all ps $>$.3). As illustrated by a comparison of Figures 5D, $7 \mathrm{E}$, and 8D, these effects had indeed a very similar left posterior scalp distribution. Finally, to verify that the LPC effect of AS was related to that of confident recognition, we computed correlations between the magnitudes of these effects. They were highly correlated with an average Pearson's $r=0.76(p=.001$; see Figure 9$)$.

Effect of emotion on ERPs in the LPC time window. Because the high AS names were rated slightly but significantly higher in emotion than the low AS names (1.8 vs. 1.35 on our $0-4$ scale, $t=3.02, p=.004$ ), we investigated if the observed LPC effect of AS was confounded by the emotionality of the names. The 120 famous names of the recognition task were split in two subsets according

Figure 7. Grand-averaged ERPs $(n=19)$ to correctly recognized old (hits) and new (correct rejections) names in the recognition memory task. ERPs were averaged across the electrodes of the frontal ROI (A), centroparietal ROI (B), and the posterior parietal ROI (C). (D and E) Spline interpolated isovoltage maps of the effect of correct recognition in the 300-500 (D) and 500-700 (E) time windows. These maps were obtained by subtracting the mean voltage of the grand mean ERPs evoked by correctly recognized new from those evoked by correctly recognized old names. 
to the emotionality scores obtained in the normative ratings. This analysis showed that the LPC did not significantly differ between names rated high versus low in emotion $(p>6)$.
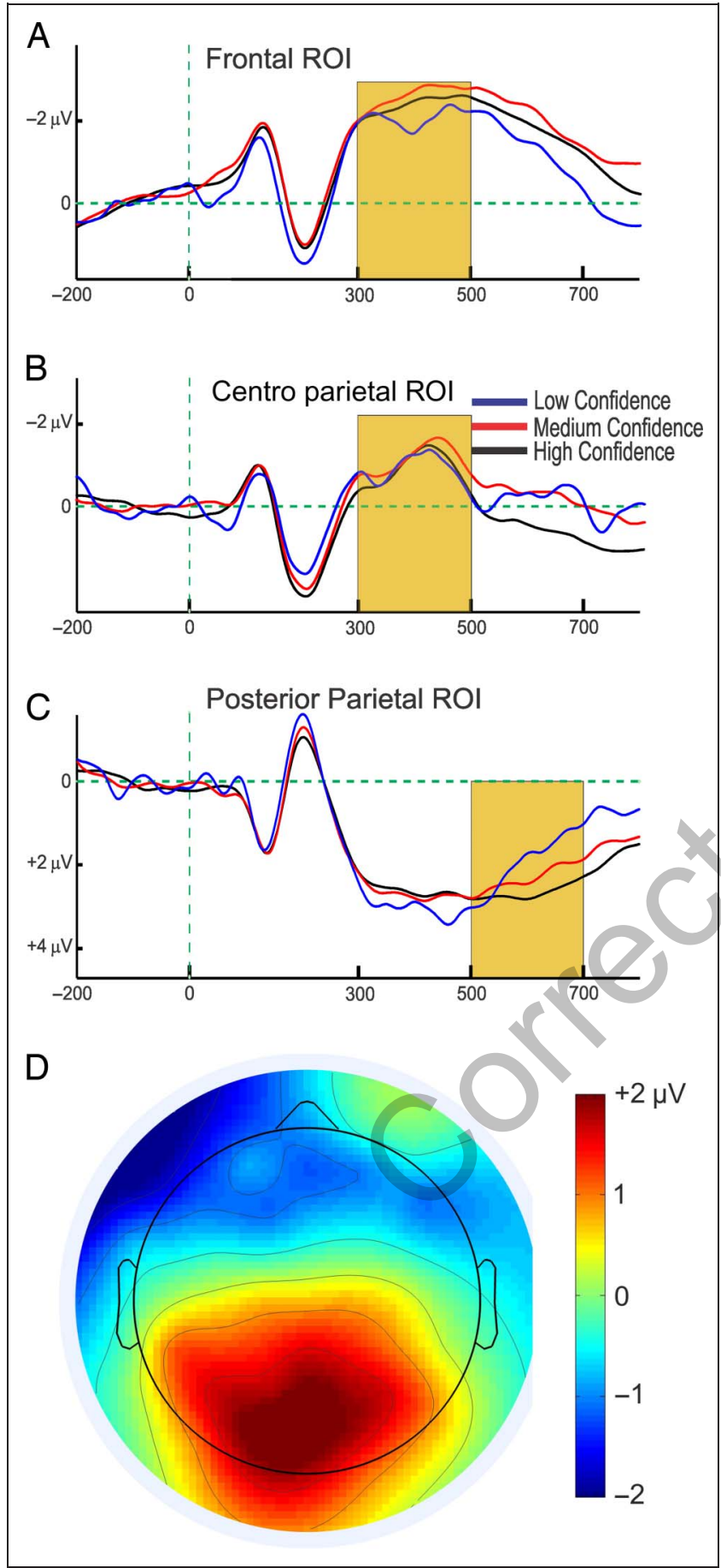

Figure 8. Grand-averaged ERPs $(n=19)$ to names assigned different degrees of recognition confidence in the recognition memory task. ERPs were averaged across the electrodes of the frontal ROI (A), centroparietal ROI (B), and the posterior parietal ROI (C). (D) Spline interpolated isovoltage maps of the effect of recognition confidence in the 500-700 time window. These maps were obtained by subtracting the mean voltage of the grand mean ERPs evoked by low confidence hits from those evoked by high confidence hits.

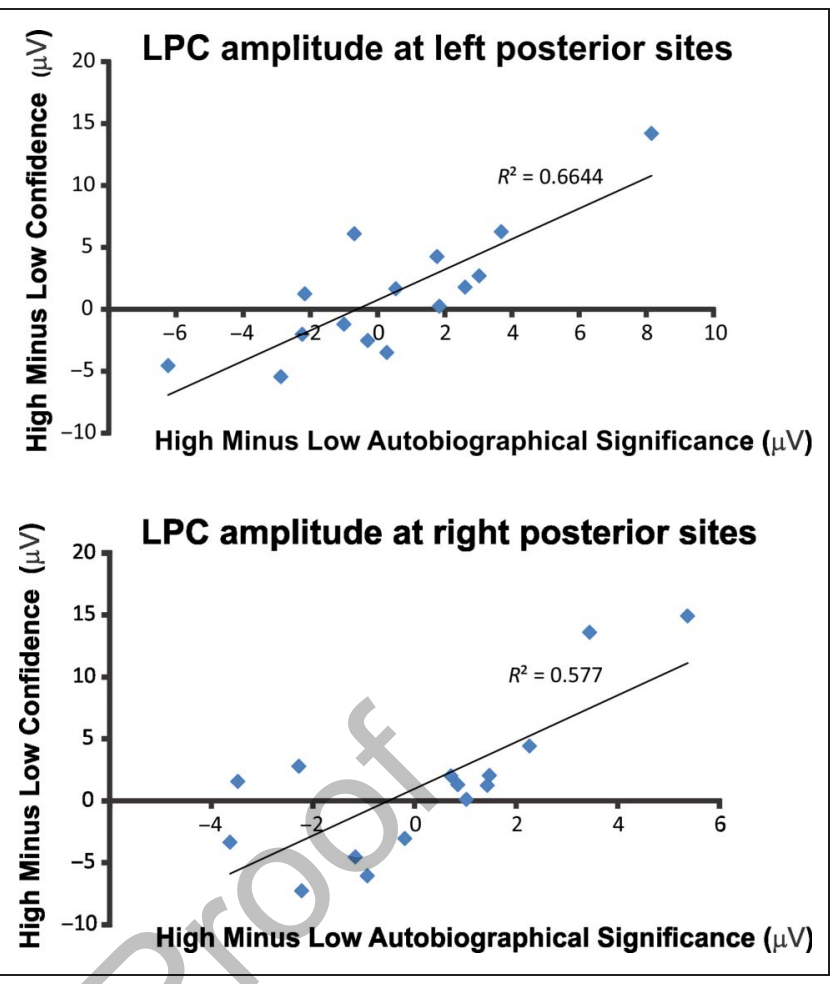

Figure 9. Mean amplitude of the parietal ROI in the LPC time window in the recognition memory task at left (A) and right (B) posterior parietal sites for the effects of AS ( $x$ axis) and recognition confidence ( $y$ axis).

The distributions are fit with linear trend lines with associated $R^{2}$ values.

Between-task comparisons of the effect of AS. We also tested if the significant difference found in the LPC effect for the high versus low AS names varied with the experimental task. Overall, the effect of AS on the LPC was significant, $F(1,18)=10.87, p=.004, \eta_{\mathrm{p}}^{2}=.37$, but it did not interact with Task $(p>.2)$ or any other factors. Very similar results were found when averaging based on the participants' own ratings, with a significant main effect of AS, $F(1,18)=5.77, p=.029, \eta_{\mathrm{p}}^{2}=.26$, but no interaction with Task $(p>.1)$.

\section{DISCUSSION}

In accordance with our hypothesis, semantic concepts high in AS also appear to have an episodic component and are associated with brain signals similar to those that are engaged by episodic memory. Compared with famous names for which participants only had general (i.e., semantic) knowledge, high AS names were associated with faster RTs on the fame judgment task and enhanced memory on the recognition memory task, replicating prior behavioral results (Westmacott \& Moscovitch, 2003). ERP results showed that, on both tasks, high AS names were associated with increased amplitude of the LPC, which is especially sensitive to retrieval success for items that are recognized with high confidence and are associated with recollection. In contrast, the N400 component, which is a 
neural correlate of semantic memory mobilization, was not significantly modulated by AS on either of the tasks. Instead, it was modulated by the NF associated with the names.

Neuropsychological studies of AS have reported a dissociation between two groups of patients: those in the early stages of semantic dementia who show a preservation of the performance advantage for high compared with low AS names and those with MTL amnesia who do not show this effect (Westmacott et al., 2001, 2004; but see Irish, Addis, Hodges, \& Piguet, 2012, on the effects of semantic loss on autobiographical memory). Using healthy adults, this study showed that AS concepts are associated with modulations of the LPC, which is associated with episodic retrieval (Voss \& Paller, 2008; Rugg \& Curran, 2007; Friedman \& Johnson, 2000), but not of the N400 component, which is associated with semantic retrieval (Kutas \& Federmeier, 2011; Lau et al., 2008; Van Petten \& Luka, 2006), nor of the FN400, which is often considered to be an index of familiarity (reviewed in Rugg \& Curran, 2007; Curran et al., 2006, but see Voss et al., 2012). Taken together, these results suggest that high AS concepts engage episodic memory more than do low AS concepts, whereas the two engage semantic memory equally. These results, therefore, do not support the hypothesis that AS concepts differ from other concepts by their inclusion of a greater number of semantic features. Crucially, the absence of N400 modulation for AS was not due to an absence of N400 effects in our participants. Consistent with previous studies, N400 amplitude was greater (Rabovsky et al., 2012; Amsel, 2011) and RTs were faster (Pexman, Hargreaves, Siakaluk, Bodner, \& Pope, 2008; Pexman, Holyk, \& Monfils, 2003) for names associated with more facts, regardless of their AS status. Moreover, we found that the association between N400 and the NF was stronger in the semantic than in the episodic task (for similar results using RT, see Pexman et al., 2008).

To corroborate that modulation of the LPC by AS status was associated with episodic memory, we found that in the recognition memory task, the LPC was modulated by task-relevant effects. Its amplitude was greater for correctly recognized old than new stimuli and was only observed for high confidence judgments, consistent with previous studies (Addante, Ranganath, \& Yonelinas, 2012; Yu \& Rugg, 2010; Woodruff, Hayama, \& Rugg, 2006). However, we showed that the modulation of the LPC is not only present in explicit memory tasks such as recognition, in which it is typically studied (Rugg \& Curran, 2007). The amplitude of the LPC was greater for personally significant names than for equally well-known but not personally significant names, both in an episodic and in an ostensibly semantic task, such as fame judgment, although AS was incidental to task performance; personal relevance was determined by a separate sample (and by the participants themselves, but after the end of the experiment). Crucially, the LPC effect of AS was highly correlated with that of recognition confidence, suggesting that similar brain processes may be at work when confronted with high AS stimuli and that the episodes attached to AS concepts may be activated automatically by them. The fact that the effect of AS modulated the LPC but not the FN400 could be interpreted as indicating that high AS concepts trigger recollective processes rather than simply eliciting familiarity-based recognition. However, this conclusion is speculative as the functional significance of the FN400 is still debated with some investigators contending that FN400 reflects conceptual priming rather than familiarity (Voss et al., 2012).

It will be interesting in future studies to specify the nature of the episodic retrieval processes reflected in the LPC effect of AS. This could involve collecting several independent measures of recollection and familiarity as well as AS for the stimuli of interest. Indeed, although LPC effects (sometimes referred to as parietal old-new effects) such as those of confidence recognition are typically assumed to reflect recollection processes (Rugg \& Curran, 2007), unless other measures are obtained, one cannot rule out the contribution of strong familiarity signals.

Because the high AS names were rated slightly but significantly higher in emotion than the low AS names (1.8 vs. 1.35 on our $0-4$ scale), the emotionality of the names might have been confounded with the effect of AS. This was not the case. The LPC did not differ for names rated high versus low in emotion. Previous studies have found effects of emotionality on components in the time range of the LPC (for a review, see Hajcak, MacNamara, \& Olvet, 2010). However, these studies compare clearly positive and negative emotions, not small variations like ours. Indeed, in our sample of famous names, we excluded any name with obvious emotional associations (murderers, victims of crimes, etc.).

In the present experiment, the fame judgment task was used as the encoding task for subsequent recognition. There could thus have been an order effect with an influence of the performance of the first task on the second one. However, the similarity of the neural correlates of AS across tasks makes this possibility unlikely: The effect of AS on the N400 was not significant in any of the tasks, whereas its effect on the LPC was significant in both and had the same left posterior maximum (maximal amplitudes at P3 and PO3) and no interaction with the Task factor was found. More generally, repeated processing of the famous names did not interfere with the effects of AS. In the fame judgment task, in which each name was repeated four times, no interaction between repetition and AS was found on behavioral and ERP measures. This is consistent with the results of Westmacott et al. (2004) and Westmacott and Moscovitch (2003) in which robust effects of AS were found in four different tasks, using the same set of names repeatedly.

Compared with other concepts, AS concepts contain distinct spatiotemporal contextual information and often include emotional salience (Denkova et al., 2006; 
Westmacott et al., 2004; Westmacott \& Moscovitch, 2003). Our results suggest that these characteristics are related to episodic memory and cannot be accounted for merely by semantic associations. These findings are consistent with the notion that conceptual knowledge may draw on (at least) two components: a generic acontextual component and an additional episodic component, which would exist not only for general concepts, such as famous names, faces, and locations (Westmacott \& Moscovitch, 2003; Westmacott et al., 2001), but also for personal artifacts, such as one's own clothing, furniture, and dishes as suggested by research on patients with semantic dementia (Snowden, Griffiths, \& Neary, 1996). Our findings on AS add to a growing body of literature on the contribution of episodic memory to domains from perception to problem solving (Moscovitch, 2008). Whereas a number of investigators have noted that semantic memory is embodied in perception and action (Barsalou, 2008; Martin, 2007), we suggest that some types of semantic memory either are embedded in episodes or closely linked to them. The evidence does not allow us to distinguish between the two, although the absence of an interaction between the AS component and the semantic component (NF) favors the linking interpretation. In either case, studying AS concepts may provide insights into how episodic memory and semantic memory interact.

\section{Acknowledgments}

Preparation of this paper was supported by the Heart and Stroke Foundation of Canada Centre for Stroke Recovery; grants from the Natural Sciences and Engineering Research Council of Canada to K. C., M. M., and P. S. R. D.; a grant from the Canadian Institutes of Health Research to B. L.; and a fellowship from the "Fonds de la Recherche en Santé du Québec" to L. R.

Reprint requests should be sent to Louis Renoult, School of Psychology, University of East Anglia, Lawrence Stenhouse Building, Norwich Research Park, Norwich, United Kingdom, NR4 7TJ, or via e-mail: L.Renoult@uea.ac.uk.

\section{Notes}

1. Vividness of a memory is typically defined as the richness and clarity with which one can recall a particular episode, including the number of sensory and contextual details and how much a person can reexperience the original event (e.g., Buchsbaum, Lemire-Rodger, Fang, \& Abdi, 2012; Addis, Moscovitch, Crawley, \& McAndrews, 2004; Rubin \& Kozin, 1984).

2. By personalities, we refer to celebrities that are famous for various or complex reasons, without one domain being especially more prominent. Examples: Terry Fox, Paris Hilton.

\section{REFERENCES}

Addante, R. J., Ranganath, C., Olichney, J., \& Yonelinas, A. P. (2012). Neurophysiological evidence for a recollection impairment in amnesia patients that leaves familiarity intact. Neuropsychologia, 50, 3004-3014.

Addante, R. J., Ranganath, C., \& Yonelinas, A. P. (2012). Examining ERP correlates of recognition memory: Evidence of accurate source recognition without recollection. Neuroimage, 62, 439-450.

Addis, D. R., Moscovitch, M., Crawley, A. P., \& McAndrews, M. P. (2004). Recollective qualities modulate hippocampal activation during autobiographical memory retrieval. Hippocampus, 14, 752-762.

Amsel, B. D. (2011). Tracking real-time neural activation of conceptual knowledge using single-trial event-related potentials. Neuropsychologia, 49, 970-983.

Bach, P., Gunter, T. C., Knoblich, G., Prinz, W., \& Friederici, A. D. (2009). N400-like negativities in action perception reflect the activation of two components of an action representation. Social Neuroscience, 4, 212-232.

Barsalou, L. W. (2008). Grounded cognition. Annual Review of Psychology, 59, 617-645.

Binder, J. R., \& Desai, R. H. (2011). The neurobiology of semantic memory. Trends in Cognitive Sciences, 15, 527-536.

Binder, J. R., Desai, R. H., Graves, W. W., \& Conant, L. L. (2009). Where is the semantic system? A critical review and meta-analysis of 120 functional neuroimaging studies. Cerebral Cortex, 19, 2767-2796.

Buchsbaum, B. R., Lemire-Rodger, S., Fang, C., \& Abdi, H. (2012). The neural basis of vivid memory is patterned on perception. Journal of Cognitive Neuroscience, 24, $1867-1883$

Cermak, L. S. (1984). The episodic semantic distinction in amnesia. In L. R. Squire \& N. Butters (Eds.), The neuropsychology of memory (pp. 52-62). New York: Guilford Press.

Cermak, L. S., \& O'Connor, M. (1983). The anterograde and retrograde retrieval ability of a patient with amnesia due to encephalitis. Neuropsychologia, 21, 213-234.

Chwilla, D. J., \& Kolk, H. H. J. (2005). Accessing world knowledge: Evidence from N400 and reaction time priming. Cognitive Brain Research, 25, 589-606.

Curran, T. (2000). Brain potentials of recollection and familiarity. Memory \& Cognition, 28, 923-938.

Curran, T. (2004). Effects of attention and confidence on the hypothesized ERP correlates of recollection and familiarity. Neuropsychologia, 42, 1088-1106.

Curran, T., \& Cleary, A. M. (2003). Using ERPs to dissociate recollection from familiarity in picture recognition. Cognitive Brain Research, 15, 191-205.

Curran, T., \& Friedman, W. J. (2004). ERP old/new effects at different retention intervals in recency discrimination tasks. Cognitive Brain Research, 18, 107-120.

Curran, T., Tanaka, J. W., \& Weiskopf, D. M. (2002). An electrophysiological comparison of visual categorization and recognition memory. Cognitive, Affective \& Behavioral Neuroscience, 2, 1-18.

Curran, T., Tepe, K. L., \& Piatt, C. (2006). ERP explorations of dual processes in recognition memory. In H. D. Zimmer, A. Mecklinger, \& U. Lindenberger (Eds.), Binding in buman memory: A neurocognitive approach (pp. 467-492). Oxford, UK: Oxford University Press.

Curran, T., Tucker, D. M., Kutas, M., \& Posner, M. I. (1993). Topography of the N400-Brain electrical-activity reflecting semantic expectancy. Electroencephalography and Clinical Neurophysiology, 88, 188-209.

Delorme, A., \& Makeig, S. (2004). EEGLAB: An open source toolbox for analysis of single-trial EEG dynamics including independent component analysis. Journal of Neuroscience Methods, 134, 9-21.

Denkova, E., Botzung, A., \& Manning, L. (2006). Neural correlates of remembering/knowing famous people: An event-related fMRI study. Neuropsychologia, 44, 2783-2791. 
Duzel, E., Vargha-Khadem, F., Heinze, H. J., \& Mishkin, M. (2001). Brain activity evidence for recognition without recollection after early hippocampal damage. Proceedings of the National Academy of Sciences, U.S.A., 98, 8101-8106.

Duzel, E., Yonelinas, A. P., Mangun, G. R., Heinze, H. J., \& Tulving, E. (1997). Event-related brain potential correlates of two states of conscious awareness in memory. Proceedings of the National Academy of Sciences, U.S.A., 94, 5973-5978.

Franklin, M. S., Dien, J., Neely, J. H., Huber, E., \& Waterson, L. D. (2007). Semantic priming modulates the N400, N300, and N400RP. Clinical Neurophysiology, 118, 1053-1068.

Friederici, A. D., Hahne, A., \& von Cramon, D. Y. (1998).

First-pass versus second-pass parsing processes in a Wernicke's and a Broca's aphasic: Electrophysiological evidence for a double dissociation. Brain and Language, 62, 311-341.

Friedman, D., \& Johnson, R. (2000). Event-related potential (ERP) studies of memory encoding and retrieval: A selective review. Microscopy Research and Technique, 51, 6-28.

Galli, G., \& Otten, L. J. (2011). Material-specific neural correlates of recollection: Objects, words, and faces. Journal of Cognitive Neuroscience, 23, 1405-1418.

Gratton, C., Evans, K. M., \& Federmeier, K. D. (2009). See what I mean? An ERP study of the effect of background knowledge on novel object processing. Memory \& Cognition, 37, 277-291.

Greenberg, D. L., Keane, M. M., Ryan, L., \& Verfaellie, M. (2009) Impaired category fluency in medial temporal lobe amnesia: The role of episodic memory. The Journal of Neuroscience: The Official Journal of the Society for Neuroscience, 29, 10900-10908.

Greenberg, D. L., \& Verfaellie, M. (2010). Interdependence of episodic and semantic memory: Evidence from neuropsychology. Journal of the International Neuropsychological Society, 16, 748-753.

Greenhouse, S. W., \& Geisser, S. (1959). On methods in the analysis of profile data. Psychometrika, 24, 95-112.

Greve, A., van Rossum, M. C., \& Donaldson, D. I. (2007). Investigating the functional interaction between semantic and episodic memory: Convergent behavioral and electrophysiological evidence for the role of familiarity. Neuroimage, 34, 801-814.

Hagoort, P., Brown, C. M., \& Swaab, T. Y. (1996). Lexical-semantic event-related potential effects in patients with left hemisphere lesions and aphasia, and patients with right hemisphere lesions without aphasia. Brain, 119, 627-649.

Hagoort, P., Hald, L., Bastiaansen, M., \& Petersson, K. M. (2004). Integration of word meaning and world knowledge in language comprehension. Science, 304, 438-441.

Hajcak, G., MacNamara, A., \& Olvet, D. M. (2010). Event-related potentials, emotion, and emotion regulation: An integrative review. Developmental Neuropsychology, 35, 129-155.

Hanslmayr, S., Spitzer, B., \& Bauml, K. H. (2009). Brain oscillations dissociate between semantic and nonsemantic encoding of episodic memories. Cerebral Cortex, 19, $1631-1640$

Heinze, H. J., Muente, T. F., \& Kutas, M. (1998). Context effects in a category verification task as assessed by event-related brain potential (ERP) measures. Biological Psychology, 47, 121-135.

Irish, M., Addis, D. R., Hodges, J. R., \& Piguet, O. (2012). Considering the role of semantic memory in episodic future thinking: Evidence from semantic dementia. Brain, 135, 2178-2191.

Klimesch, W., Schimke, H., \& Schwaiger, J. (1994). Episodic and semantic memory: An analysis in the EEG theta and alpha band. Electroencephalography and Clinical Neurophysiology, 91, 428-441.
Kutas, M., \& Federmeier, K. D. (2011). Thirty years and counting: Finding meaning in the N400 component of the event-related brain potential (ERP). Annual Review of Psychology, 62, 621-647.

Kutas, M., \& Iragui, V. (1998). The N400 in a semantic categorization task across 6 decades. Evoked PotentialsElectroencephalography and Clinical Neurophysiology, 108, 456-471.

Laszlo, S., \& Federmeier, K. D. (2011). The N400 as a snapshot of interactive processing: Evidence from regression analyses of orthographic neighbor and lexical associate effects. Psychophysiology, 48, 176-186.

Lau, E. F., Phillips, C., \& Poeppel, D. (2008). A cortical network for semantics: (De)constructing the N400. Nature Reviews Neuroscience, 9, 920-933.

Liu, Y., Perfetti, C. A., \& Hart, L. (2003). ERP evidence for the time course of graphic, phonological, and semantic information in Chinese meaning and pronunciation decisions. Journal of Experimental Psychology: Learning, Memory and Cognition, 29, 1231-1247.

Lopez-Calderon, J., \& Luck, S. J. (2014). ERPLAB: An open-source toolbox for the analysis of event-related potentials. Frontiers in Human Neuroscience, 8, 213. Luck, S. J. (2005). An introduction to the event-related potential technique. Cambridge, MA: MIT Press.

Manning, L., Denkova, E., \& Unterberger, L. (2013). Autobiographical significance in past and future public semantic memory: A case-study. Cortex, 49, 2007-2020.

Martin, A. (2007). The representation of object concepts in the brain. Annual Review of Psychology, 58, 25-45.

Moscovitch, M. (2008). The hippocampus as a "stupid," domain-specific module: Implications for theories of recent and remote memory, and of imagination. Canadian Journal of Experimental Psychology: Revue Canadienne De Psychologie Experimentale, 62, 62-79.

Moscovitch, M., Rosenbaum, R. S., Gilboa, A., Addis, D. R., Westmacott, R., Grady, C., et al. (2005). Functional neuroanatomy of remote episodic, semantic and spatial memory: A unified account based on multiple trace theory. Journal of Anatomy, 207, 35-66.

Muller, O., Andoni Dunabeitia, J., \& Carreiras, M. (2010). Orthographic and associative neighborhood density effects: What is shared, what is different? Psychophysiology, 47, 455-466.

Niedeggen, M., Rosler, F., \& Jost, K. (1999). Processing of incongruous mental calculation problems: Evidence for an arithmetic N400 effect. Psychophysiology, 36, 307-324.

Olichney, J. M., Van Petten, C., Paller, K. A., Salmon, D. P., Iragui, V. J., \& Kutas, M. (2000). Word repetition in amnesiaElectrophysiological measures of impaired and spared memory. Brain, 123, 1948-1963.

Pexman, P. M., Hargreaves, I. S., Siakaluk, P. D., Bodner, G. E., \& Pope, J. (2008). There are many ways to be rich: Effects of three measures of semantic richness on visual word recognition. Psychonomic Bulletin \& Review, 15, $161-167$

Pexman, P. M., Holyk, G. G., \& Monfils, M. H. (2003). Numberof-features effects and semantic processing. Memory $\mathcal{E}$ Cognition, 31, 842-855.

Rabovsky, M., Sommer, W., \& Abdel Rahman, R. (2012). The time course of semantic richness effects in visual word recognition. Frontiers in Human Neuroscience, 6, 11.

Rahman, R. A., \& Sommer, W. (2008). Seeing what we know and understand: How knowledge shapes perception. Psychonomic Bulletin \& Review, 15, 1055-1063.

Renoult, L. (in press). Semantic memory: Behavioral, electrophysiological and neuroimaging approaches. To appear In D. F. Marques \& J. A. Toscano (Eds.), From 
Neurosciences to Neuropsychology - the study of the buman brain. Corporación Universitaria Reformada.

Renoult, L., Davidson, P. S. R., Palombo, D. J., Moscovitch, M., \& Levine, B. (2012). Personal semantics: At the crossroads of semantic and episodic memory. Trends in Cognitive Sciences, 16, 550-558.

Rubin, D. C., \& Kozin, M. (1984). Vivid memories. Cognition, 16, 81-95.

Rubin, D. C., Schrauf, R. W., \& Greenberg, D. L. (2003). Belief and recollection of autobiographical memories. Memory $\&$ Cognition, 31, 887-901.

Rugg, M. D., \& Curran, T. (2007). Event-related potentials and recognition memory. Trends in Cognitive Sciences, 11, 251-257.

Ryan, L., Cox, C., Hayes, S. M., \& Nadel, L. (2008). Hippocampal activation during episodic and semantic memory retrieval: Comparing category production and category cued recall. Neuropsychologia, 46, 2109-2121.

Senkfor, A. J., \& Van Petten, C. (1998). Who said what? An event-related potential investigation of source and item memory. Journal of Experimental Psychology: Learning Memory and Cognition, 24, 1005-1025.

Sheldon, S., \& Moscovitch, M. (2012). The nature and timecourse of medial temporal lobe contributions to semantic retrieval: An fMRI study on verbal fluency. Hippocampus, 22, 1451-1466.

Smith, M. E. (1993). Neurophysiological manifestations of recollective experience during recognition memory judgments. Journal of Cognitive Neuroscience, 5, 1-13.

Snowden, J. S., Griffiths, H. L., \& Neary, D. (1996). Semanticepisodic memory interactions in semantic dementia: Implications for retrograde memory function. Cognitive Neuropsychology, 13, 1101-1137.

Squire, L. R. (2004). Memory systems of the brain: A brief history and current perspective. Neurobiology of Learning and Memory, 82, 171-177.

Stenberg, G., Hellman, J., Johansson, M., \& Rosen, I. (2009). Familiarity or conceptual priming: Event-related potentials in name recognition. Journal of Cognitive Neuroscience, $21,447-460$.

Swaab, T., Brown, C., \& Hagoort, P. (1997). Spoken sentence comprehension in aphasia: Event-related potential evidence for a lexical integration deficit. Journal of Cognitive Neuroscience, 9, 39-66.

Tulving, E. (2002). Episodic memory: From mind to brain. Annual Review of Psychology, 53, 1-25.
Van Petten, C., \& Luka, B. J. (2006). Neural localization of semantic context effects in electromagnetic and hemodynamic studies. Brain and Language, 97, 279-293.

Vilberg, K. L., Moosavi, R. F., \& Rugg, M. D. (2006). The relationship between electrophysiological correlates of recollection and amount of information retrieved. Brain Research, 1122, 161-170.

Voss, J. L., Lucas, H. D., \& Paller, K. A. (2012). More than a feeling: Pervasive influences of memory without awareness of retrieval. Cognitive Neuroscience, 3, 193-207.

Voss, J., \& Paller, K. A. (2008). Neural substrates of remembering-Electroencephalographic studies. In J. Byrne (Ed.), Learning and memory: A comprebensive reference (Vol. 3, pp. 79-97). Oxford: Elsevier.

Westmacott, R., Black, S. E., Freedman, M., \& Moscovitch, M (2004). The contribution of autobiographical significance to semantic memory: Evidence from Alzheimer's disease, semantic dementia, and amnesia. Neuropsychologia, 42, $25-48$.

Westmacott, R., Leach, L., Freedman, M., \& Moscovitch, M. (2001). Different patterns of autobiographical memory loss in semantic dementia and medial temporal lobe amnesia: A challenge to consolidation theory. Neurocase, 7, 37-55.

Westmacott, R., \& Moscovitch, M. (2003). The contribution of autobiographical significance to semantic memory. Memory \& Cognition, 31, 761-774.

Wilding, E. L. (2000). In what way does the parietal ERP $\mathrm{old} / \mathrm{new}$ effect index recollection? International Journal of Psychophysiology, 35, 81-87.

Wilding, E. L., \& Rugg, M. D. (1996). An event-related potential study of recognition memory with and without retrieval of source. Brain, 119, 889-905.

Woodruff, C. C., Hayama, H. R., \& Rugg, M. D. (2006). Electrophysiological dissociation of the neural correlates of recollection and familiarity. Brain Research, 1100 , 125-135.

Yick, Y. Y., \& Wilding, E. L. (2008). Material-specific neural correlates of memory retrieval. NeuroReport, 19, 1463-1467.

Yonelinas, A. P. (2002). The nature of recollection and familiarity: A review of 30 years of research. Journal of Memory and Language, 46, 441-517.

Yu, S. S., \& Rugg, M. D. (2010). Dissociation of the electrophysiological correlates of familiarity strength and item repetition. Brain Research, 1320, 74-84. 